\title{
First aid for a unique acid, HF: A sequel
}

\section{By Eileen B. Segal}

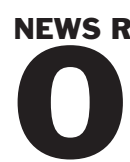

ctober 22, 1999: Robert Belk, a 48-year-old business owner, died at Grady Memorial Hospital after an exposure to hydrofluoric acid. Belk owned a company called Chemical Packaging near Atlanta, GA, which produced solutions for high-pressure washing. At the time of the accident, Belk was mixing a solution when a hose slipped out, saturating his clothes with $70 \%$ hydrofluoric acid. He hosed off with water, but rather than have his secretary call the paramedics, he drove himself to the hospital! Burns were found on both lower legs and his left arm, but it was the HF which went through his skin that caused his death the following day from respiratory and heart failure. $^{1}$

The above accident, which occurred just before submission of this paper, illustrates a dire consequence of working with hydrofluoric acid without awareness of its extreme hazards and lack of preparedness. From the nu-

\footnotetext{
Eileen B. Segal is a private consultant (Segal Consults, 2701 Liberty St., Easton, PA 18045, 610258-2656; ebsegal@aol.com) in the field of chemical health and safety and in technical editing. She was an analytical chemist for DuPont and the GAF Corp., and for the past 19 years has conducted seminars in chemical health and safety throughout the United States and Canada as part of the J.T. Baker Office of Training Services.
}

merous queries I personally have received after publication of my first paper in $1998,{ }^{2}$ I conclude that there are still many more who could use information. And from a recent spate of inquiries on the SAFETY listserve, it appears that many have not established a protocol for HF exposure or heard of the current recommended methods of treatment. So a review/ update to my first paper seems appropriate. In this sequel I want to discuss:

\section{Review of HF hazards}

II. Emergency procedures

III. Treatments

IV. 5 vs. 15 minutes of irrigation

V. Current status of Hexafluorine

\section{REVIEW OF HF HAZARDS}

Hydrofluoric acid (CAS 7664-39-3) is a high-volume chemical used in at least eight industries (see Figure 1), with production of 375,000 tons in 1998 and demand estimated to be 400,000 tons in the U.S. in $2002 .^{3}$ It is considered more hazardous than most chemicals in five out of six ranking systems $^{4}$; it is ranked as one of the most hazardous compounds (worst $10 \%$ ) to human health. Ray Campbell, REA, CCHO, at Varian, Inc., described his HF injury as "the most painful, disabling, scarring, long-term injury I have ever seen, and I am a Vietnam veteran." Concentrated HF covering $2 \%$ of the body can be fatal.

$\mathrm{HF}$ is a colorless, fuming liquid or gas with a strong, irritating odor. In concentrated forms it is a strong protonic acid, whereas dilute solutions are weak acids $\left(\mathrm{pK}_{\mathrm{a}}=3\right)$ that remain relatively nonionized but can penetrate the stratum corneum, the tough waterproof outer skin layer of dead cells, and penetrate deep into tissue layers. ${ }^{5}$ Once absorbed HF dissociates rapidly at the physiological $\mathrm{pH}$ of 7.4.

$$
\mathrm{HF} \rightarrow \mathrm{H}^{+}+\mathrm{F}^{-}
$$

Toxic systemic effects occur when the electron-hungry fluoride ion penetrates and migrates into tissue to bind primarily with calcium, but binding to magnesium, sodium, and potassium can also occur.

$$
\begin{gathered}
\mathrm{Ca}^{2+}+2 \mathrm{~F}^{-} \rightarrow \mathrm{CaF}_{2} \\
\mathrm{Mg}^{2+}+2 \mathrm{~F}^{-}+\rightarrow \mathrm{MgF}_{2}
\end{gathered}
$$

Without enough calcium (hypocalcemia) and magnesium (hypomagnesia), nerves fail and cell membranes collapse. In addition, excess potassium (hyperkalemia) can occur, which can lead to life-threatening cardiac arrythmias (ventricular fibrillation). The adverse effects can progress for several days after exposure.

Surface involvement of weak solutions is minimal and may even be absent. Burns to the fingers and nail beds may leave the overlying nails intact. An insidious hazard is the fact that dilute solutions are indistinguishable from water.

The time to onset of symptoms is related to the concentration of the HF:

- At concentrations $>50 \%$ : immediate burns appear with rapid destruction of tissue as noted by a whitish discoloration, usually proceeding to blisters, accompanied by severe pain. The pain is typically described as "deep," "burning," or "throbbing," and often out of proportion to apparent skin involvement.

- At concentrations between 20 and $50 \%$ : burns can be delayed 1 to $8 \mathrm{hr}$. 


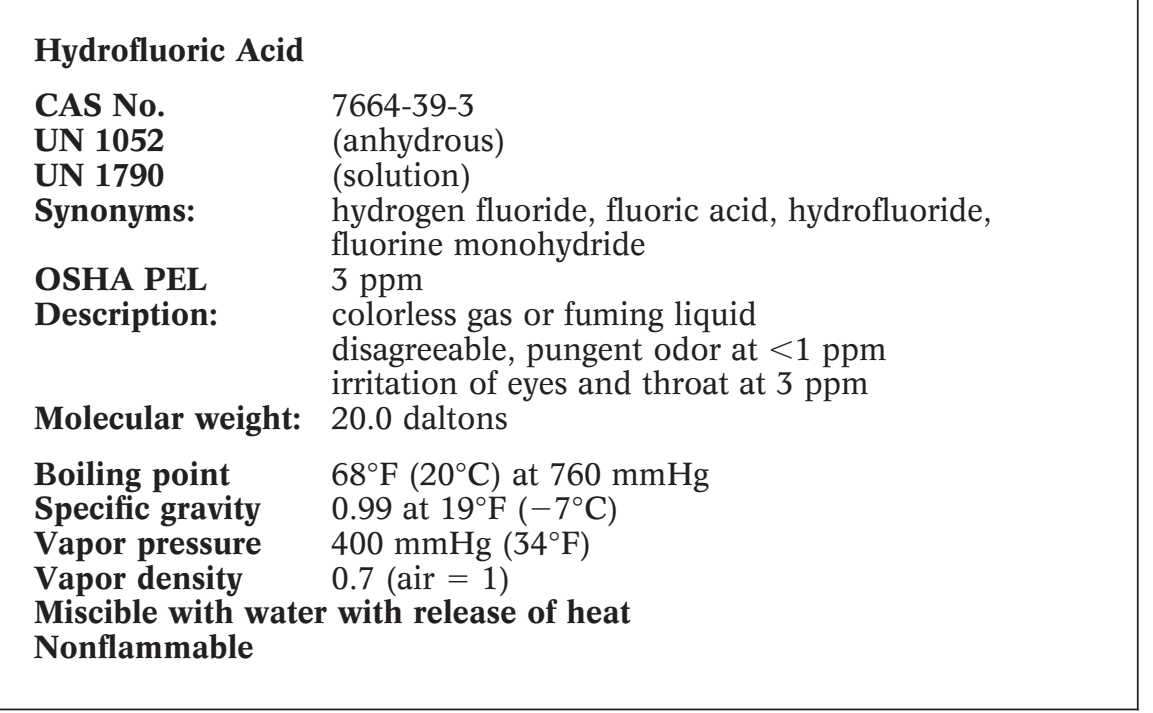

- At concentrations <20\%: painful erythema may be delayed for up to 24 hr. Redness, burning, or pain may not show up until several minutes or even hours have elapsed. Thus the surface area of the burn is not predictive of effects.

\section{EMERGENCY PROCEDURES}

Standard first aid for most corrosives is to flush the exposed area with water for $15 \mathrm{~min}$. Then treatment by a professional can be administered. However, because of the dire consequences of HF exposures, the following first aid is recommended (based mainly on procedures used by AlliedSignal $^{6}$ ).

\section{A. Skin Contact}

1. Immediately (within seconds) shower or flush with plenty of water.
2. Remove all clothing while in the shower (remove goggles last; double-bag contaminated clothes).

3 . If $2.5 \%$ calcium gluconate gel or $0.13 \%$ benzalkonium chloride is available, rinsing may be limited to $5 \mathrm{~min}$ [this is sufficient time to effectively remove HF from the skin; additional flushing time is unnecessary and will delay further treatment]. If neither neutralizing agent is on hand, continue to flush until medical help is available.

4. Continue with either step a or step b. a. Apply calcium gluconate gel $(2.5 \%)$ while wearing impervious gloves. Massage the gel promptly and repeatedly into burned area until pain is relieved. If pain does not subside within 20 to $30 \mathrm{~min}$, injections of $5 \%$ calcium gluconate by a professional may be needed. b. Immerse affected area in iced $0.13 \%$ benzalkonium chloride (Zephiran). Use ice cubes, not shaved ice in order to prevent frostbite. If immersion is not practical, use towels soaked with iced $0.13 \%$ benzalkonium chloride as compresses for the burned area. Change compresses every 2 to $4 \mathrm{~min}$. Continue until pain is relieved (this may require hours).

5. Get medical help.

\section{B. Breathing Vapor}

1. Immediately get to fresh air.

2. Call or have someone call a physician.

3. Breathe $100 \%$ oxygen (10 to 12 $\mathrm{L} / \mathrm{min}$ flow rate) as soon as possible.

4. Trained personnel should provide calcium gluconate $(2.5 \%)$ by nebulizer.

5. Get medical attention.

\section{Ingestion}

1. Drink large amounts of water. Do not induce vomiting or administer activated charcoal.

2. Drink several glasses of milk or several ounces of milk of magnesia, Mylanta, Maalox, or similar product, or up to 30 Tums, Caltrate, or other antacid tablet.

3. Get immediate medical attention.

\section{Eye Contact}

Because of the ability of HF to penetrate deep into tissue, exposure of $\mathrm{HF}$ solution or vapor to the eye can produce more extensive damage than that of other acids in similar concentra-

\section{Industry}

Electroplating

Etching

Flotation Agents

Integrated Iron and Steel Manufacturing

Laboratory Chemicals

Oil Refineries

Refrigeration

Semiconductors

Home Use: Air-conditioning unit coil cleaners; aluminum automotive wheel cleane cleaners; masonry cleaners; rust stain remover; truck and commercial car washing compounds; water spot remover.

\author{
Use \\ Acid Metal Cleaners-Oxide Removers \\ Glass Etching and Frosting \\ Depressants-Nonsulfide Ores \\ Pickling Acids \\ Acids, Other Chemicals (non-salts) \\ Catalyst to Produce High-Octane Fuel Additives \\ Manufacture of Fluorocarbons \\ Wet Chemical Etching
}

Figure 1. Uses for HF. 


\title{
FIRST AID FOR HYDROFLUORIC ACID BURNS TO THE EYE(S)
}

\author{
Bernard Blais, M.D., F.A.A.O., F.A.C.O.E.M., F.A.C.S.
}

(1) IT IS IMPERATIVE that immediate and thorough treatment be provided at the EARLIEST possible time.* Alert emergency personnel.

(2) Immediately utilize emergency deluge showers and/or emergency eyewashes ${ }^{\dagger}$ based on the amount or area of contamination to the body.

(3) The employer's first responders must be trained in first aid for hydrofluoric acid burns, including the use of $0.13 \%$ benzalkonium chloride and $2.5 \%$ calcium gluconate gel and calcium gluconate intravenous solution (first responders per OSHA are to be trained to service the potential hazards).

(4) Upon arrival at the scene, first responders should evaluate the victim for potential cardiovascular or pulmonary complications, and initiate emergency medical treatment based on the existing emergency medical services protocol.

(5) Whereas initial irrigation of a corrosive with deluge shower or emergency eyewash generally lasts 15 minutes, in the case of HF burns, it is 5 minutes prior to further medical treatment or until relieved by emergency personnel. Clothing, jewelry, and shoes should be removed during the showering period, removing chemical goggles last over head and eyes closed. Normally, individuals tend to close their eyes when flushing, so it is important to hold the eyelids open and have the victim roll the eyeballs so water will flow to all surfaces.

(6) It is critical to irrigate beneath the eyelids, not just

the face and external surfaces of the eyelids. It is important not only to flush away the caustic substance, but also to remove any particulate matter that may have lodged under the eyelids.

(7) A device such as a Morgan Lens or, preferably, an Eye Irrigator can be used with a standard Ringers solution containing $1.0 \%$ calcium gluconate and a local anesthetic for HF ocular burns. The Eye Irrigator ${ }^{\ddagger}$ is a fairly new device, consisting of a slitted loop designed to easily slide up under the upper lid without having to pry open or otherwise traumatize the eye. The procedure is simple but does require some basic training. Benzalkonium chloride solutions should not be used for ocular burns.

(8) Eye irrigation should be continued by the first responder until relieved by a physician, preferably by an ophthalmologist. Calcium gluconate should not be injected subconjunctivally or subtenons, because it is too toxic for ocular tissue.

(9) The ophthalmologist may elect to continue irrigation with $500-1000 \mathrm{~mL}$ of $1 \%$ calcium gluconate solution utilizing a local anesthetic. Depending on the severity of the injury, the patient may be admitted to hospital or discharged with a topical application of $1 \%$ calcium gluconate eye solution, ophthalmic steroids, antibiotics (systemic or topical), and other treatments for alkali corrosive eye burns such as glaucomatous agents for elevated intraocular pressure.

* Subpart K-Medical and First Aid of OSHA $\$ 1910.151$ states:

(a) The employer shall ensure the readily availability of medical personnel for advice and consultation on matters of plant health. (b) In the absence of an infirmary, clinic, or hospital in near proximity to the workplace which is used for the treatment of all injured employees, a person or persons shall be adequately trained to render first aid. First aid supplies approved by the consulting physician shall be readily available.

(c) Where the eyes of body of any person may be exposed to injurious corrosive materials, suitable facilities for quick drenching or flushing of the eyes and body shall be provided within the work area for immediate emergency use.

${ }^{\dagger}$ See ANSI Z358.1-1998 guidelines, Emergency Eyewash and Shower Equipment.

‡The Eye Irrigator is available from American Health and Safety, P.O. Box 46340, 6250 Nesbitt Rd., Madison, WI 53744-6340, (800) 522-7554. A 5-min. training video is available.

Dr. Blais is an Occupational Ophthalmologist, an Eye M.D., and Chairman of the Eye and Vision Committee of the American College of Occupational and Environmental Medicine (ACOEM), Consultant and Liaison to American Academy of Ophthalmology for ACOEM, Clinical Professor of Ophthalmology, Albany Medical College.

tions. E.g., hydrochloric acid damages only the superficial structures of the eye, because its penetration is limited by a precipitated protein barrier. ${ }^{5}$ In the case of HF, immediate action should be taken with initial flushing and then treatment with sterile $1 \%$ calcium gluconate solution. For de- tails, see the inset by Bernard Blais, M.D.

\section{TREATMENTS}

Calcium gluconate is the preferred treatment of choice for minor HF exposure for the following reasons:
- It is easy to use.

- It can be self-administered or applied by first aiders.

- It can be applied immediately as soon as the burn is suspected.

- It is painless to apply.

- It produces no risk of increasing tension in the tissues. 
- It can be used topically, infiltrated, inhaled, and ophthalmically.

- It reduces the risk of hypocalcemia.

- No sophisticated equipment is necessary.

Pharmascience Inc. is the main supplier of calcium gluconate and can be contacted at 8400 Darnley Rd., Montreal, Quebec H4T 1M4, Canada. In the U.S. the company has a distributor at 175 Rano St., Buffalo, NY 14207 (800-207-4477, orders; 800-363-8805, technical information). Calcium Gluconate Gel is available in 25-g tubes in multiples of 12 for $\$ 264.60$ in the U.S. Quantities of 6 are available for \$165.30. A 5\% freight and handling charge is applicable.

\section{A. Mixing Your Own Solutions}

This method can be considerably cheaper or a local pharmacy can make up a solution.

1. Topical Gel (2.5\%). Mix one $10-\mathrm{mL}$ ampule $(10 \%)$ per ounce of surgical gel (K-Y Lubricating Jelly; Johnson \& Johnson). The gel must be kept above $40^{\circ} \mathrm{F}$. Do not freeze.

The latest DuPont MSDS (Nov 1998) supplies another formulation as well: Mix $3.5 \mathrm{~g}$ of USP calcium gluconate powder with a $5-\mathrm{oz}$ tube of surgical water-soluble lubricant (e.g., K-Y Lubricating Jelly).

2. Calcium Gluconate Solutions for Topical Injections. Mix one 10 -mL ampule $(10 \%)$ with an equal amount of saline solution to give a $5 \%$ calcium gluconate concentrate.

3. Nebulizer. Mix one $10-\mathrm{mL}$ ampule $(10 \%)$ per $30 \mathrm{~mL}$ of saline solution to give a $2.5 \%$ calcium gluconate solution.

4. Eye Wash. Mix one $10-\mathrm{mL}$ ampule $(10 \%)$ per $90 \mathrm{~mL}$ of saline to get a $1 \%$ calcium gluconate solution. If you take $100 \mathrm{~mL}$ out of a $1000-\mathrm{mL}$ bag of normal saline and put in $100 \mathrm{~mL}$ of calcium gluconate, you will have the proper mixture.

Note: The shelf-life for all mixtures has not been determined, but a periodic replacement period should be established; the recommendation on the DuPont MSDS is 6 months. If the ingredients are stored separately until needed, the shelf-life is less of a concern.

Be aware that even following emergency treatment with calcium gluconate, delayed life-threatening burns can still occur. Followup treatment at a medical facility is necessary. It is wise to warn the hospital of your intentions to bring folks to them for HF burn treatment and to make sure that they are informed of its specific treatment.

\section{It is wise to warn the hospital of your intentions to bring folks to them for HF burn treatment and to make sure that they are informed of its specific treatment.}

\section{B. Benzalkonium Chloride (Zephiran Solution)}

This product can be obtained from Sanofi Inc., 90 Park Ave., New York, NY 10016 (800-446-6267). It is available in gallon containers as a 1:750 $(0.13 \%)$ solution. The material has a limited shelf-life and should be stored in light-resistant containers. A $17 \%$ solution is also available but should only be diluted by a qualified individual. Since benzalkonium chloride is a nonprescription drug, it should be available through most local pharmacies. They can obtain it from pharmaceutical wholesale distributors such as McKesson Pharmaceuticals, Cardinal Health Inc., or the local pharmaceutical wholesaler. Assorted basins should be kept on hand for immersions.

\section{5 vs. 15 MINUTES OF IRRIGATION}

After my first paper was published, ${ }^{2}$ a letter to the editor was published in the Jan./Feb. 1999 issue of $C H \& S$ entitled, "Another viewpoint on the treatment of HF skin exposure."7 The purpose of the letter was to "provide an interpretation of these different procedures and offer a practical response for HF skin procedure." Points brought out follow:

- It is straightforward to train employees in a single emergency response treatment (i.e., the common 15-min wash protocol).

- Recommendations in MSDSs are inconsistent.

- There is a real possibility that a confused employee will attempt to apply HF treatment to another acid, (e.g., $\mathrm{HCl})$.

- Community-involvement programs stress communication with industrial users of HF and hospitals.

All the above are valid statements, but considering DuPont's claim,

Flushing with water thoroughly for 5 min is sufficient to effectively remove HF from skin. Additional flushing time is unnecessary and will delay further treatment. Although flushing is effective in removing surface acid, it does not affect the $F^{-}$that may have already penetrated.

we have a dilemma. Will an exception to the rule for HF cause confusion? The solution is, of course, to have a plan in effect ahead of time, and to provide training to implement that plan. All potentially exposed personnel should be trained in first-aid care for HF burns before beginning work with HF. Calcium gluconate gel should be readily accessible in areas where HF exposure potential exists.

DuPont provides all its potentially exposed personnel with a $\left(3^{\prime \prime} \times 5^{\prime \prime}\right)$ booklet and card $\left(2.25^{\prime \prime} \times 3.75^{\prime \prime}\right)$, easily carried on their persons. These are routinely provided free of charge to companies purchasing HF and to anyone who requests a single copy (call 800-441-9408).

My contact at DuPont informed me that the 5-min wash procedure began in 1990 and since that time at least $75 \%$ (it might be as high as $98 \%$ ) of companies using anhydrous HF have adopted the 5-min wash. Further, he 
tells me that the 5-min wash is being applied to other water-soluble substances such as hydrochloric acid and chlorine. The DuPont MSDSs for hydrochloric acid and chlorine state for skin contact, "Flush the skin thoroughly with water at least 5 minutes." Preliminary tests show that the 5-min time frame is effective in many cases; this is especially fortuitous in cold areas where a 15-min cold shower wreaks its own hazards.

And consider this! In 1998 Pharmascience introduced a new product, a sterile $2.5 \%$ isotonic calcium gluconate wash packaged in a plastic container $(480 \mathrm{~mL})$. In the event of an exposure, the solution was to be applied immediately to affected areas until thoroughly washed. It was claimed that the wash removed more HF than a pure water wash and significantly reduced the quantity of HF that penetrated the skin. After washing, calcium gluconate gel was to be applied repeatedly while seeking medical attention. Evidently HF users weren't ready for this innovation and as of Aug. 6, 1999, the wash was no longer available.

\section{CURRENT STATUS OF HEXAFLUORINE}

At the 1998 spring meeting of the Semiconductor Safety Association, Hall et al. delivered a paper ${ }^{8}$ that presented impressive results about the use of Hexafluorine, a proprietary product manufactured by Laboratoire PREVOR in France, claimed to be an amphoteric, hypertonic, chelating agent specifically designed to detoxify hydrofluoric acid. It has chemical bond energy greater than that of eye/ skin receptors and does not produce a significant exothermic reaction with release of heat that could further damage exposed tissue. In addition, it is claimed to be safe to use in the eyes. Hall describes five cases in his paper. Two of those cases follow:

1. A worker fell into a bath containing $1505 \mathrm{~L}$ of water, $30 \mathrm{~L}$ of concentrated hydrochloric acid, and $233 \mathrm{~L}$ of $59 \% \mathrm{HF}$ (calcd bath concn, 9.2\% HF), immersing his entire body and face. Hexafluorine, as well as a regular water eyewash, was immediately used for decontamination by coworkers, Only minor burns developed on the back and abdomen, there was a significant corneal burn of the left eye, but the right eye remained normal.

2. At a facility using a chemical dipping bath containing nitric acid and HF for producing stainless steel for construction and machine tools, a worker sustained an eye splash with $38 \%$ HF. He rinsed his eye immediately with Hexafluorine and did not develop any eye injury, returning to work the next day.

Experimental animal data on rats and rabbits as well as in vitro data are compelling. One such case is shown in Figure 2. To simulate the effects of decontamination without flushing, 10 $\mathrm{mL}$ of $0.1 \mathrm{~N} \mathrm{HF}(0.2 \%)$ was placed in a beaker and either water, $10 \%$ calcium gluconate, or Hexafluorine was added. The $\mathrm{pH}$ and the $\mathrm{pF}(\mathrm{pF}=$ negative logarithm of the fluoride ion concentration) were measured. As noted, water had little effect. Both calcium gluconate and Hexafluorine absorbed or neutralized $\mathrm{H}^{+}$, although Hexafluorine bound the hydrogen ion 100 times greater than calcium glu-

\begin{tabular}{|l|l|l|}
\hline & $\mathrm{pH}$ & $\mathrm{pF}$ \\
\hline Water & Little change & Little change \\
\hline $10 \%$ calcium gluconate & 4.5 & 3 \\
\hline Hexafluorine & 6.5 & 6 \\
\hline
\end{tabular}

Figure 2. Experimental Results.

conate. The final $\mathrm{pH}$ for Hexafluorine was 6.5 vs. 4.5 (still acidic) for calcium gluconate.

I recently spoke with Alan Hall, M.D., one of the authors of the 1998 paper on Hexafluorine, who has been hired as a consultant for PREVOR. He was very skeptical about the product at the beginning, but new incidents of 11 exposed workers at Mannesmann AG (headquartered in Dusseldorf, Germany) have shown the effectiveness of the product. These case studies will be presented at the Semiconductor Safety Association 2000 spring meeting and published. ${ }^{9}$

\section{One should always try to keep up to date to learn of new innovations in safety, especially when working with nasty chemicals such as HF, and then institute those changes if they can save lives.}

Hexafluorine is being widely used in France and Germany; Ireland, Italy, Sweden, and the United Kingdom are giving serious consideration to its use. In the U.S., PREVOR is actively seeking FDA approval, armed with the new compelling data from Germany. One "sticky" issue is whether the product should be considered a drug or, preferably, a medical device (as it is in Europe).

For more information on PREVOR, check out the web site at http://www. prevor.com.

\section{CONCLUSION}

Because HF is a unique acid and its emergency treatment is specialized and different from that of other inorganic acids, all exposed and poten- 
tially exposed personnel should be made familiar with its properties and hazards and trained ahead of time to deal with emergency situations. In the case of the HF fatality mentioned in the introductory news report, the victim evidently was not aware of the internal damage that the fluoride ion could inflict. Protocols should be set up, appropriate supplies should be on hand, and arrangements should be made with nearby hospitals and professionals because not all physicians may be aware of the unique treatments. In addition, one should always try to keep up to date to learn of new innovations in safety, especially when working with nasty chemicals such as $\mathrm{HF}$, and then institute those changes if they can save lives. Even if you've already converted to a 5-min rinse and have calcium gluconate on hand, don't get complacent; new and better changes may be coming. Stay on top of safety!

\section{Acknowledgments}

I want to thank Dr. Bernard Blais for his contribution to this article and acknowledge AlliedSignal and DuPont for their valuable comments, assistance, and generosity in sharing information.

\section{References}

1. Kelley, S. The Gwinnett Daily Post, Oct. 23, 1999, p. 1. Web site: http://www. gwinnettdailypost.com/gdp10231999/ fpals2-gdp.htm.

2. Segal, E. B. "First aid for a unique acid: HF", Chem. Health Saf. 1998, 5, 25-28. Also on the Web: http://dchas. cehs.siu.edu/Magazine/hf.

3. "Chemical Market Reporter", Chemical Profile of Hydrofluoric Acid, Oct. 1999, Schnell Publishing, New York, NY.

4. Chemical Scorecard, Environmental Defense Fund, New York, NY, 1999.
5. Caravati, E.M., Am. J. Emerg. Med. 1988, 6(2), 143.

6. "Recommended Medical Treatment for Hydrofluoric Acid Exposure," Dec. 1998, AlliedSignal Inc., P.O. Box 1053, 101 Columbia Rd., Morristown, NJ 07962-1053. This booklet can be obtained at no charge by calling $800-622$ 5002 or faxing your request to $973-455-$ 6141. For more information, check out AlliedSignal's web site at http://www. specialtychem.com/ha/.

7. Langerman, N. Chem. Health Saf. 1999, 6(1), 5 .

8. Hall, A. H.; Blomet, J.; Gross, M.; Nehles, J. "Hexafluorine ${ }^{\circledR}$ for Emergency Decontamination of Hydrofluoric Acid (HF) Eye/Skin Splashes." Presented at the Semiconductor Safety Association Meeting, San Diego, CA, March 1999. Funded by Laboratoire PREVOR, Moulin de Verville, Valmondois, France.

9. The meeting will be held in Arlington, VA, April 25-28. For more information, check out the SSA web site: http:// semiconductorsafety.org.

\section{Additional Resources}

\section{- Interesting case studies}

1. Brown, J., "An Invisible Fire", Discover, April 1996, pp 88-90.

2. Detailed Coroner's Report of a Fatal Accident in Australia, 1994: McCann, D. A., Coroner, Coroner's Court, Grain Pool Building, 172 St. George's Terrace, Perth 6000, West Australia.

\section{- For large-volume users}

Guidelines from the Hydrogen Fluoride Industry Practices Institute (HFIPI), a subsidiary of the CMA: Recommended Practices for the Hydrogen Fluoride Industry, 3 vols. These guidelines are only sold in sets of \$100 each, including shipping and handling (additional cost for interna- tional shipping); they cannot be purchased individually. For more information or to order, contact Hydrogen Fluoride Practices Institute, Attn. Reid Dennis, 3050 K St., NW, Suite 400, Washington, DC 20007: tel 703-7415619; fax 703-741-6091.

\section{- Sample Protocols}

The following have offered to share their protocols, which can be adapted to your work site.

Thomas J. Shelley at Cornell University,607-255-4285; e-mail tjs@cornell. edu. URL: http://www.ehs.cornell. edu/lrs/cheminfo/infopackets/hf.htm.

Debbie M. Decker at University of California, Davis, 530-754-7964: dmdecker@ucdavis.edu. URL: http:// ehs.ucdavis.edu. Check on "Safety Nets" and search for \#70.

\section{- Medical Information}

U.S. Department of Human Services, Public Health Service, Agency for Toxic Substance and Disease Registry, "Medical Management Guidelines for Acute Chemical Exposures," 8/1/ 92; updated 4/12/99: http://aepo-xdvwww.epo.cdc.gov/wonder/prevguid/ p0000016/body015.htm\#head00500 6000000000 .

Wilkes, G. "Hydrofluoric Acid Burns," updated 4/11/99: http:// emedicine.com/emerg/topic804.htm.

\section{- Slide presentation}

A set of 40 slides on HF geared toward the laboratory worker is available from the University of Delaware: http://www.udel.edu/OHS/chemical/ hfpresent/sld001.htm. 


\section{HF First Aid}

\section{First aid for a unique acid: HF}

Eileen B. Segal

Segal Consults, 2701 Liberty St., Easton, PA 18045-2620

Date: April 30, 1998. An emergency on the popular TV program ER dealing with a security guard exposed to hydrofluoric acid (HF) prompted a good deal of discussion on various first-aid treatments. In the show, the man died. Could he have been saved if proper first-aid and medical treatment had been given promptly?

ER is fiction, but the truth is many deaths have resulted from exposure to HF. In the United States, more than 1000 cases of HF exposures are reported annually, but the actual number of exposures is unknown. Thus, a review of current emergency practices seems prudent, as there are questions regarding the best therapy.

Conventional first aid for exposures to all acids has been to rinse with water for $15 \mathrm{~min}$, even longer for HF, and then get medical treatment from professionals. Although studies and experience have shown that $\mathrm{HF}$ requires a different approach from other acids, a review of a significant number of material safety data sheets has revealed the same standard emergency treatment--water, water, and more water. Newer recommended procedures call for immediate flushing, but limited to 5 min, followed by by treatment from emergency responders.

\section{Mode of action}

HF is a mean character or as a professor of chemistry was heard to say. "Fluorine can rip a proton off your grandmother." Hydrofluoric acid is an extremely hazardous liquid; it can cause severe skin and eye irritation or deep-seated, slow-to-heal burns.

The insidious hazard is that symptoms may be slow to appear, depending on the concentration, and thus treatment may be delayed. At concentrations above $50 \%$, immediate skin destruction is apparent by a white, marble-like discoloration accompanied by excruciating pain; the discoloration usually proceeds to blister formation. With $20-50 \%$ solutions, burns and pain can be delayed for 1 to $8 \mathrm{~h}$; at concentrations of less than $20 \%$, painful erythema (redness of the skin) may be delayed for $24 \mathrm{~h}$. Concentrations as low as $2 \%$ may catse symptoms if skin contact is long enough.

HF's mode of action is to bind calcium whenever contact occurs with skin of other body tissues. In the air-tissue interface, HF penetrates cells as the moleculc. Once absorbed, it forms soluble salts which are fully dissociable: 


$$
\mathrm{HF}=\mathrm{H}^{+}+\mathrm{F}
$$

The dissociation is extremely fast and is highly favored at the physiological $\mathrm{pH}$ of 7.4. The fluoride ion is the villain, and it can cause liquefaction necrosis (consistent with alkali damage, not acid. damage) of soft tissue and destruction of the supporting tissue by forming insoluble calcium fluoride.

$$
2 \mathrm{~F}^{\prime}+\mathrm{Ca}^{2 \cdot}=\mathrm{CaF}_{2}
$$

Unlike the action of other acids, which are rapidly neutralized, tisstue destruction and neutralization of HF may proceed for days. Although flushing is effective in removing surface acid, it does not affect the F which may have already penetrated. Because calcium is necessary for cell life, its binding can bring about cell death in a short time. If the exposure covers a large amount of skin surface, excessive amounts of calcium may be inactivated, so that inadequate amounts of $\mathrm{Ca}^{2 *}$ are available for vital body functions. This causes hypocalcemia, in which heart function is diminished, heart beat becomes abnormal, and cardiac arrhythmia (ventricular fibrillation) can occur. Liver and kidney damage may also occur.

The fluoride ion can also bind to magnesium to form insoluble MgF2:

$$
2 \mathrm{~F}+\mathrm{Mg}^{2+}=\mathrm{MgF}_{1}
$$

The binding of magnesium causes hypomagnesemia, an abnormally low magnesium content of the blood plasma, which can cause neuromusculat hyperirritability (a pathological response of muscles and nerves to slight stimuli).

Also to be considered is the formation of other soluble fluorinated salts:

$$
\begin{aligned}
& \mathrm{Na}^{*}+\mathrm{F}=\mathrm{NaF} \\
& \mathrm{K}^{*}+\mathrm{F}=\mathrm{KF}
\end{aligned}
$$

These salts are very toxic at high concentrations, They act as direct cellular poisons by interfering with enzyme mechanisms.

Fingertip injury may cause persistent pain and result in bone loss and nail-bed injury. The healing of skin burns may be prolonged, and extensive scarring may occur.

\section{Acute Toxicity}

There are similarities and dissimilarities between the effects of exposure to $\mathrm{HF}$ and exposure to other types of acids 
Skin. Like other acids, the extent of injury depends on the amount, concentration, duration of contact, part of the body contacted, and temperature. The toxic effects of $\mathrm{HF}$ are primarily due to $\mathrm{F}$, which can penetrate tissues and bind intracellular calcium and magnesium. Severe burns can be caused by exposure to concentrated HF $(350 \%)$ on $1 \%$ or more of the body surface, and to any concentration of HF on at least $5 \%$ of the body surface. Initial signs of damage are redness, edema, and blistering. The severe throbbing pain of burns is thought to be due to irritation of nerve endings by increased levels of potassium ions entering the extracellular space to compensate for the reduced levels of calcium ions, which have been bound to the fiuoride. Dilute solutions of HF penetrate deeply before dissociation. Surface involvement is minimal and may even be absent.

Respiratory tract. Concentrated solutions and anhydrous hydrofluoric acid produce pungent fumes upon contact with air. These fumes can cause nasal congestion and bronchitis, even in low concentrations. Burns that occur when the vapors or liquid contact to the oral mucosa or upper airway may cause severe swelling, to the point of airway obstruction requiring a tracheostomy. Acute symptoms from inhalation exposure are coughing, choking, and nose and throat irritation, followed (after an asymtomatic period of 1-2 days) by chitls, fever, difficulty in

bteathing, and cyanosis. Anyone with symptoms should be hospitalized for observation and/or treatment. As with dermal exposure, pulmonary edema may be delayed for several hours, even up to two days. This is likely in patients with burns of the face and neck. Pulmonary edema that does not respond to medical treatment may be fatal.

Gastrointestinal tract. If HF is ingested, severe burns to the mouth, esophagus, and stomach can result, with severe pain, bleeding, vomiting, diarthea, and collapse of blood pressure. Systemic effects can also occur. A number of deaths have occurred after even small amounts of $\mathrm{HF}$.

Eyes. Hydrothuric acid can cause severe eye burns, with destruction or opacification of the cornea. Blindness may result from severe or untreated exposures. Immediate first aid and specialized medical care are necessary,

\section{Chronic toxicity}

The fluoride ion is considered the major concern from a chrotuic toxicity standpoint. Long-term, exposure to high levels of fluoride salts in water can cause mottling of teeth in children, fluorosis of bone, and sometimes osteosclerosis in adults and children. HF is not considered a developmentai or reproductive hazard, although there have been rare cases of mottiing of first teeth in infants born to mothers who had high daily intakes of fluoride during pregnancy. However, low doses of fluoride are thought to be essential for normal fetai development in 
humans. HF is not listed as a carcinogen or suspected carcinogen by the International Agency for Research on Cancer, the National Toxicology Program, OSHA, or the American Conference of Governmental Industrial Hygienists.

\section{First-aid treatments}

When exposures are promptly and successfully treated, results are generally favorable. improper treatment can result in permanent damage, disability, or death. Treatment is directed toward binding of the fluoride ion to prevent tissue destruction. Speed is of the essence. Alt potentially exposed personnel should be trained in its handling, and first-aid actions should be planned before beginning work with $\mathrm{HF}$.

AlliedSignal inc, the world's leading supplier of $\mathrm{HF}$, provides a pamphlet, "Recommended Medical Treatment for Hydrofluoric Acid Exposure" (latest edition, July 1996). The company has shared its information broadly and has provided hundreds of free copies of the informative booklet (call 1-800-622-5002 for a copy). The treatments specified for contact or suspected contact follow.

\section{- Skin contact}

I. Move victim immediately to safety shower or other water source and flush affected area thoroughly with large amounts of cool running water.

\section{Remove all contaminated clothing while flushing.}

3. Rinsing may be limited to 5 min if $0.13 \%$ benzalkonium chloride solution or $2.5 \%$ calcium gluconate gel is available, with the soaks or gel applied as soon as the rinsing is stopped. If not available, rinsing must continue until medical treatment is rendered.

4. While the victim is being rinsed with water, someone should alert first-aid or medical personnel and arrange for subsequent treatment.

5. Immediately after thorough washing, use one of the measures below:

a. Begin soaking the affected areas in iced $0.13 \%$ benzalkonium chloride solution. Use ice cubes, not shaved ice, in order to prevent frostbite.

If immersion is not practical, towels should be soaked with iced $0.13 \%$ benzalkonium chloride solution and used as compresses for the bumed area. Compresses should be changed every 2 to 3 mir. Soaks or compresses should be continued until pain is relieved or until more definitive medical treatment is provided. Relief of pain is an indication of the success of treatment, therefore, local anesthetics should be avoided.

b. Start massaging $2.5 \%$ calcium gluconate gel into the burn site. Apply gel every $15 \mathrm{~min}$ and massage continuously until pain and/or redness 
disappear or until more definitive medical care is given. It is advisable for the applier to wear surgical gloves.

Note: Clinical experience has shown that both benzalkonium chloride and calcium gluconate gel are effective when used correctly in appropriate situations. In an animal model, benzalkonium chloride soaks appear to be superior to calcium gluconate gel under the experimental conditions used (see Durn et al., 1992, 1996).

6. After treatment of burned areas is begun, the victim should be examined to ensure there are no other burn sites which have been overlooked.

7. Arrange to have victim seen by a physician. Continue soaks or massaging.

- Eye contact.

1. Immediately flush the eyes for a least 15 min with large amounts of gently flowing water. Hold the eyelids open and away from the eye during irrigation to allow thorough flushing of the eyes. Do not use benzalkonium chloride solutions described for skin treatment. If sterile $1 \%$ calcium gluconate is available, washing may be limited to $5 \mathrm{~min}$, after which the $1 \%$ calcium gluconate solution should be used repeatedly to irrigate the eye using a syringe.

2. Take the victim to a doctor, preferably an eye specialist, as soon as pussible. Ict-water compresses may be applied to the eyes while transporting the victim (see the box on eye treatment).

- Inhalation

1. Immediately move victim to fresh air and get medical attention.

2. Keep victim warm, quiet, and comfortable.

3. If breathing has stopped, start artificial respiration at once: Make sure mouth and throat are free of foreign material and the airway is open.

4. Oxygen should be administered as soon as possible by a trained individual. Continue oxygen while awaiting medical attention.

5. A nebulized solution of $2.5 \%$ calcium gluconate may be administered with oxygen by inhalation.

6. Do not give stimulants unless instructed to do so by a physician.

7. The victim should be examined by a physician and held under 
observation for at least $24 \mathrm{~h}$

8. Vapor exposures can cause skin and mucous membrane burns as well as damage to pulmonary tissue. Vapor burns to the skin are treated the same. as liquid HF burns.

\section{- Ingestion}

1. Have the victim drink large amounts of water as quickly as possible to dilute the acid. Do not induce vomiting. Do not give emetics or baking soda. Never give anything by mouth to an unconscious person.

2. Give several glasses of milk or several ounces of milk of magnesia, Mylanta, Maalox, or the like. The calcium or magnesium in these compounds may act as an antidote.

\section{Get immediate medical attention}

\section{Other first-atd information}

DuPont. DuPont's MSDS, dated Sept. 19, 1995, states, "Flush skin thoroughly with water for 5 minutes. Flushing with water thoroughly for 5 minutes is sufficient to effectively remove HF from skin. Additional flushing time is unnecessary and will delay further treatment."

DuPont has a tectinical information booklet, "Hydrofluoric Acid/ Anhydrous, Technical: Properties, Uses, Storage, and Handling," which it shares with the public. In addition, DuPont has prepared a $3 \times 5$ booklet and a $2.25 \times 3.75^{\prime \prime}$ card with first-aid information for distribution to its customers and potentially exposed personnel.which can easily be carried on their persons (see box for a copy of the card).

Mallinckrodt Baker. This company is another supplier of HF; its MSDS advises a 15-20-min wash and then treatment with Hyamine 1622 (tetracaine benzethonium chloride) or $0.13 \%$ Zephiran Chloride (benzalkonium chloride). However, the MSDS provides a "Note to Physician" in its section on first-aid measures for an alternative first-aid procedure, stating;

"It has been conclusively shown [references given] that flushing the affected area with water for one minute and then massaging $\mathrm{HF}$ Antidote $\mathrm{Gel}$ (contains calcium gluconate) into the wound until there is a cessation of pain is the most effective first aid treatment available. HF Antidote Gel is available in 2.5-g tubes... We recommend that any person in contact with HF should carry, or have access to, a tube of HF Antidote Gel at all times; ideally with one tube at the workplace, one on the person" and one at home. For safety's sake, we believe that HF Antidote Gel should be issued to all employees who may come into contact with $\mathrm{HF}:$ 
To obtain an MSDS from Mallinckrodt Baker, call 1-800-JIBAKER or 908-859-6911 and follow the voice prompts to obtain information by fax (the catalog number is 6904 ).

\section{HF panacea?}

French reseorchers have produced an antidote for HF called Hexafluorine; It is an amphoteric binding agent which they claim enables it to absorb HF rapidly (a few seconds), preventing the superficial layers of skin from destruction and creating a natural protection against fluoride advance. They claim the "fluoride bound by Hexafluorine is 100 times stronger than when captured by calcium. They also claim that it is safe to use in the eyes.

Hexafluorine has been used in Europe and is now available through a distributor in the U.S. It seems to be a very effective treatment but it has not been opproved by the Food and Drug Administration; without FDA backing, legal liabilities become a concem. A lack of sufficient documentation, together with the product's high cost ( $\$ 1500$ for a fire-extinguisher type dispenser), would be deterrents to its use. For those who would like more information, the U.S. vendor, Prevor, has a Web page at http:/ / www.prevorusa.com.

\section{Conclusion}

Because of the seriousness of exposure to $\mathrm{HF}$, the sooner it is rendered ineffective, the better. The procedures of AlliedSignal have been very effective, that is, a shorter flush time and faster application of calcium gluconate or benzalkonium chloride. At one time, the availability of these substances was a problem. Now calcium gluconate can be ordered in many local pharmacies and is available from Pharmascience Laboratories, 175 Rano St, Buffalo, NY 14207 (1-800-207-4477), Cost: $625-\mathrm{g}$ tubes, $\$ 27,55 /$ tube; $1225-\mathrm{g}$ tubes, $\$ 22.05 /$ tube. Benzalkonium chloride is sold by Sanofi Winthrop Pharmaceutical, New York, NY.

In this age of litigation, a problem for some may well be a prohibition or reluctance to allow anyone other than a trained or licensed protessional to administer any kind of medication. On the other hand, liability may be a larger issue in the case of bodily harm or even death for withholding what is considered an effective treatment:

Employers should make assessments, ute up-to-date procedures, and establish a protocol for their workplaces. It is important that all potentially exposed personnel, first-aid responders, and medical stoff be trained ahead of time in the chosen protocal. 
Back to the fictitious security guard on ER: All we know is that the victim was beyond saving by the time he reached the hospital. Would he have been spared if emergency responders had begun treatment at the scene? It makes one wonder. Anyone dealing with HF should be prepared for that type of emergency. You don't want to change fiction into

reality,

Acknowledgment. I am especially grateful to personnel at AlliedSrgnal and DuPont for stimulating discussions and materials. Both companies were generous in sharing their information. Thanks are due to Dr.

Bermard Blais for many personal discussions and his contribution to this article,

Copyright to 1999 ACS, Division of Chemical Health and Safety. All rights reserved. dchas@cehs.siu.edu 

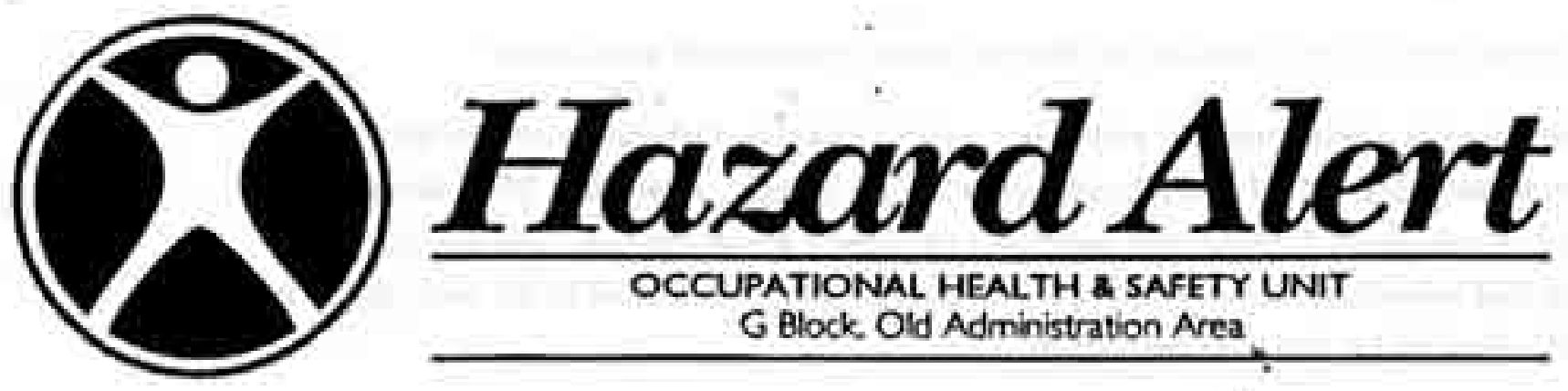

OCCUPATIONAL HEALTH \& SAFETY UNIT

$G$ Block, Old Administation Area

\section{6 (1995)}

\section{Hydrofluoric Acid, HF}

Hydrogen fluoride is extremely corrosive. It is a fuming, colouriess liguid at normat atmospheric pressure and less than $19^{\circ} \mathrm{C}$. Above $19^{\circ} \mathrm{C}$, hydrogen fluoride is a gas. Hydrogen fluoride is industrially available as a liquid under pressure (anhydrous hydrofluoric acid) or more commonly, as an aqueous solution (aqueous hydrofluoric acid (HF)), with a concentration in the range of $30-70 \%$ HF w/v 111 . The most common concentration for analytical grade HF is $48 \%$ HF w/v $(2)$.

Hydrofluoric acid is commonly used for digesting minerals. etching glass, and as a fuorinating agent, metal pickling, and more.

4

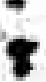

Hydrofluoric acid exposure[\$] may be -

Acute (short term).

s Spillage on the skin, or spiash in the eyes. This causes; intense pain, either immediately or after some hours, a tough white coagulation over the burnt area (a slow healing uleer), and progressive destruction of tissue including decalcification and necrosis of bone. A $2 \%$ (approximately $360 \mathrm{~cm}^{2}$ ) body bum from $70 \%$ hydrofluoric acid may cause death.

The eyes are especially sensitive.

it Inhalation of gas or mists, leading to asphyxia from pulmonary oedema (fluid in the lungs) and convulsions.

A Ingestion, burning of mouth and pharynx, nausea, vomiting, abdominal pain.

Chronic (long term) -

म Skin ulcers,

of Bone and teeth damage,

मे Irritation of nose, throat and bronchi.

Chronic poisoning is not common. 
A recent incident $[4]$ demonstrates just how dangerous hydrofluotic acid can be -

Whilst siting at a fume cupboard processing mineral samples, a laboratory technician knocked approximately $100 \mathrm{~mL}$ of hydrofuoric acid onto his thighs. Immediate $10 \%$ body burns ensued, despite rapid fushing with water and emergency hospitalisation. The following week his leg was amputated, however, the individual eventually succumbed to the toxic effects of the HF. He died 15 days afler the accident.

Several factors coniributed to the accident -

- Failure to protect the skin from exposure with appropriate clothing:

- Failure to restrain containers of HF in secure holders.

- Failure to apply neutralising cream.

- Lack of emergency planning/Iacilities/personnel.

- Poor work station design.

Recommendations (ehock these against your work place) -

E Ensure that personnel are familiar with the properties and hazards of dangerous chemicals.

Gollow appropriate safe work practices.

Plan work in the knowledge that any exposure may cause permanent incapacity or death.

Where practicable substifute with a less dangerous substance.

D Use minimum quantities.

Train workers in safe procedures, personal protection and first aid/emergency procedures in accordance with the WorkSafe Guide on Hydrogen Fluoride 1989 [5].

C Ensure approprinte personal protective equipment is used. This shall include: a face shieid (or safety glasses): a PVC apron: natural, butyl nubber or PVC gloves. Note: these gloves materials all degrade in the presence of HF - inspect and replace before they break.

$\square$ Ensure that safety showers, eye wash facilities and calcium gluconate gel are available wherever HF is used.

D All work should be conducted in a fume cupboard.

$\square$ Person should not work alone with HF.

Additional information -

D. Contaminated clothing should be washed with bicarbonate of soda solution.

D Contaminated equipment should be neutralised with calcium hydtoxide, before being washed with water:

- Containers should be stored away from heat and in well ventilated areas, Ideally it should stored in a secondary container.

D. Special acid gas respirators are required to treat spills, outside a fume cupboard.

Additional information is available from the OHS Unit: 


\section{FIRST AID PROCEDURES}

Treatment for Hydrofluoric acid[3]

\section{SKIN}

a) Remove contaminated elothing and deluge the burnt areas with water.

b) Seek emergency medical treatment.

c) Apply calcium giuconale gel on and around the bum. Massage it in with clean fingers (preferably gloved), until IS minutes after the pain has subsided. This may require several hours, but continue massaging with the gel so long as there is improvement in the symptoms.

d) Where a thick necrotic coagulum (dead tissue mass) has formed, this should be removed and the gel then massaged into the base of the burn, taking aseptic precautions.

c) If the burn fails to respond to the gel, injection of a $10 \%$ calcium gluconate into and under the burn should be considered. The quantity injected will be governed by the relief of pain.

f. Local anaesthesia is contra-indicated, so that the splitting of finger and toe nails should be performed under general anaesthesia.

g) The burns may not require dressing, but where they do, use the caleium gluconate gel.

h) Advise the patient to return for further treatment if the pain recurs.

i) Treat symptomatically.

\section{EYES}

a) Irrigate with copious quantities of isotonic saline or water.

b) Seck emergency medical treatment.

c) Instil sterile calcium gluconate drops, $10 \%$.

d) Treat symptomatically.

\section{INHALATION}
a) Remove to fresh air.
b) Artificial respiration and oxygen is necessary.
c) Remove to hospital by ambulance accompanied by the Material Safety Data Sheet.
d) Continue observation for 48 hours because of the dangers of pulmonary oedema.

\section{INGESTION}

a) Give copious quantities of lime water, milk or water drinks (in spite of vomiting).

b) Remove to hospital by ambulance accompanied by the Material Safety Data Sheet.

c) Intravenous injection of $10 \mathrm{~mL}$ of $10 \%$ calcium gluconate repeated hourly and given stowly, 


\section{SERUM ELECTROLYTE REPLACEMENT}

In large bums of over $160 \mathrm{~cm}^{2}$, or in cases of ingestion and severe inhalation. calcium and/or magnesium may be severely reduced in the blood serum.

Give calcium and ascorbic acid in water by mouth every two hours untill admitted to hospital. Frequent electrolyte monitoring will decide future conduct in the case.

Keep this sheet accessible for an emergency.

References:

(1) Patty's Industrial Hygiene and Toxicology, Vohame 28: Toxicology, $3^{\text {rd }}$ edition, 1981. John Willey \& Sons, USA

[2] BDH Laboratory Suppiies 1994/95, Merek Fry Ltd.

[3] Environmental $\&$ Industrial Health Hazardh, a Proctical Guide, R.A. Trevethick, $2^{\text {nd }}$ edition, 1980. William Heinernana Medical Books Ltd, London.

[4] Sigaineant Ineident Summary, Department of Occupational Heath, Safety and Welfare. WA.

[5] WoekSafe Austratia Guide, Hydrogen Fluoride, 1989. 

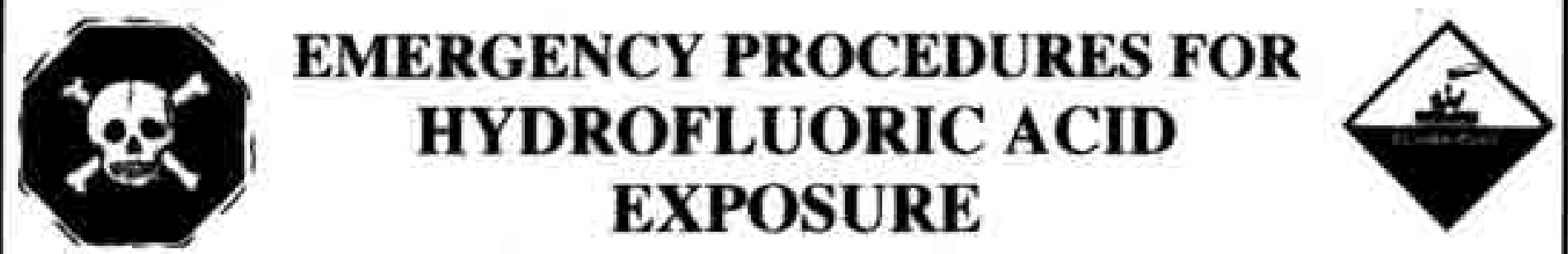

\section{SEEK IMMEDIATE MEDICAL ATTENTION CALL 9-911}

\section{SERIOUS TISSUE DAMAGE WITH DELAYED ONSET}

\section{BEGIN FIRST AID IMMEDIATELY}

\section{FIRST AID FOR SKIN CONTACT}

1. IMMEDIATELY (within seconds) proceed to the NEAREST SAFETY SHOWER. While showering REMOVE ALL CONTAMINATED CLOTHING and WASH THE AFFECTED AREA FOR 5 MINUTES.

2. USING NITRILE 22 MIL (MFG. RECOMMENDED) GLOVES MASSAGE CALCIUM GLUCONATE GEL. into the affected area. If

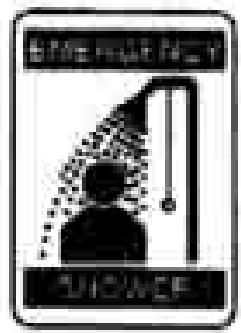
calcium gluconate gel is not available, wash area for at least 15 minutes or until emergency medical assistance arrives.

3. RE-APPLY CALCIUM GLUCONATE GEL and massage it into affected area EVERY 15 MINUTES until medical assistance arrives or pain disappears.

\section{FIRST AID FOR EYE CONTACT}

1. IMMEDLATELY (within seconds) proceed TO THE NEAREST EYEWASH STATION.

2. Thoroughly WASH EYES WTTH WATER FOR AT L.EAST 15 MINUTES while holding eyelids open.

3. DO NOT APPLY CALCIUM GLUCONATE GEL TO EYES.

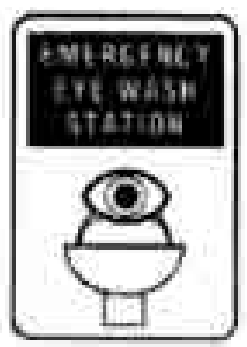

\section{FIRST AID FOR INHALATION}

$\downarrow$ GET MEDICAL ASSISTANCE by calling 9-911. 
EHS TIPS

Tochnical intumaton \& Practical Sathions

HYDROFLUORIC ACID

May 2000

\section{FATALITY DUE TO ACUTE HYDROFLUORIC ACID EX- POSURY}

A fatal aceident occurred in a laboratory in Australis in 1993. reaulting in the death of a tochuician. The techniciun was scated when he knocked over a small quantity (between 100 and 230 mi) of hydrofluoric acid (HF) oeto his lap, splashing both thighs.

The technician sustained burns to $9 \%$ of his body, despite washing his legs with water at 6 liters/min No calciuan glucotiate gel was applied to the affected area and contaminatod clothing was not removed dariag the flushing with water. His rigbt leg was amputated 7 days after the incident. He subsequantly died from multiorgan failure 15 days after the hydrofluoric acitt spilt.

Investigation showed that this death eoull have been prevented if appropriate emargency procedures, safety cquipment and personal protective equipment had been available during the handling of concentrated HF.

University of Washington

Environmental Health and Safety Box 354400

wwo,ehs.rashington.edu

Hydrofluoric acid (HF) is an extremely corrosive acid used for many purposes including mineral digestion, surface cleaning, etching, and biological stainins. HF's anique properties inake if significantly more tazardous thun many of the other acids used on campus. This TIPS Sheet discusses how to protect yourself against the dangers of HF. Attached you will also find emergency procedures for dealing with HF exposures. Please pont these procedures wherever HF is used or hatidied.

\section{HEALTH HAZARDS}

The health hazands of HF depend upon the type of exposure and the concentration.

\section{EVx AND SikI ExPOSUR:}

HF is corrosive and readily destroys tis. sue. HF exposure to the eyes may result in blindness or permanent eye damage. HF readily persetrates haman skin, allowing it to destroy soff tissues and decalcify bone. Chemical bums from HF are typically very painful and slow to heal. Skin exposure to highly concentrated HF (approximately $50 \%$ or greater) immediately results in serious and painful destruction of tissue.

If the exposure covers a large amount of skin surface area, excessive amounts of calcium can be inactivated leading to systemie fluoride poisoning, hypocalcemia, and hypomagnescmia. Heart funetion is diminished in bypoealeemia (reduced calcium levels in the blood), whereby the heartbeat becomes sbeormal, and cardiac arrhythmia (ventriculat fibrillation) can occur. Liver and kidney damage may also occur in high exposure conditions. Hypomagnesemia leads to neuromuscular hyperimitability (a pathological response of museles and nerves to slight stimuli).

One of HF's most insidtious properties is that skin contact at lower concentrationts may not produce pain or burning sensations until hours after the exposure. Because of the ability of HF to produce delayed setious tissue damage without secessarily producing pain, all skin, eye, or tissue contact with HF should recelve IMMEDIATE first aid and medical evaluation even if the injury appears miner or no pain is felt.

\section{INHALATION OF HF VAPOH}

Inhaling HF vapors can seriously dumage the lunge. Delayed reactions up to and including fatal puimonaty edema (flooding of the lumgs with body fluids) may not be apparent for bours after the initial exposure. The Waulington industrial Safety Health Administration (WISHA) limits employees' exposure to uitbome conectstrations of HF to 3 parts per milhnn (ppm) ceiling limit that should not be exceeded at any time, Airborne concentrations of 10-15 ppm will imtate the eyes, skin, and respinatory tract. A concentration of 30 ppm is considered "Immediately Dangerous to Life and Health" (IDL.H) and may have irreversible bealth effects. At uirborne concentrations above $50 \mathrm{ppm}$, even brief exposure may be fatal.

\section{CHRONIC HIF EXPOSURE}

Long-term or chronic exposure to HF may result in fluorosis, a syndrome characterized by weight loss, bone embrittlement, anemia, and general ill bealth.

\section{SAFETY PRECAUTIONS FOR HE USE}

\section{EMFLOVEE INFORMATION AND}

\section{TRANANC}

Employees who handle HF must receive documented training on the hazarts of HF and what to do in the event of an exposure ot a spill. A Material Safety Data Sheet (MSDS) on HF should always be kept in the immediate wotk area where HF is used. The MSDS together with this TIPS Sheet are an excellent basis for training employees an the hazards of HF, Periodic refresher training should be provided, including procedures to follow in an emergency and wbete to find the caleium gluconate geL. EH\&S can offer assistance in providing this training. Please call 543.7201 for further information.

\section{SAYE Work Practices}

If possible, avoid working alone when you're using HF. Do not eat, smoke, or drink where $\mathrm{HF}$ is handied, since the chernical can be swallowed. Wash hands thoroughty after handling HF. Refer to your lab standard operating procedures for more information.

\section{STORAGE}

Store all HF and $\mathrm{HF}$ waste in labeled chernically compatible containers (c.g. polyethylene or Teflon'M). Glass, metal, and ceramic containers are NOT compatible with HF, HF should never be stored with incompatible chenicals such as ammonia or other alkaline materials. Always place HF on a low protected shelf or other location where it will not be acci. dentally spilled of knocked over

\section{Waste}

HF waste should be placed in a labeled chemically compatible container with a screw cap lid. Complete a Haxardous Waste Collection Form, and send it to EH\&S (Box 354400 or fax 685-2915) 
Call EH\&S (685-2848) if you need any. waste labels or forms or have any ques. tions regarting the disposal of HF waste. See the EH\&S web site for more information on waste disposal

(wwwebs washingtonedu)

\section{RESPIRATOAY PROTECTION}

HF should be used with adequate ventilation to minimize inhalation of vapor. Concentrations greater than $5 \%$ should always be handled inside a properly funetioning chemical fume bood. FH\&S can evaluate work practices and monitor airborne levels of HF, upon request (543-7388)

\section{EYe Protrction}

Always use chemical goggles together with a face shield when handling eoncentrated HF. Due to HF's highly corrosive nature, safety glasses with side shields do not ptovide adequate eyo protection.

\section{Bopy Photrction}

Wear a laboratory coat with a chemical splash aprea made out of natural rabber, nooprene, or viton. Never wear shorts or open-toed shoes when bandling HF.

\section{HAND PROTECTION}

Typically, a 22 mil. gauge viton or nitrile gloves are worn when working with HF. Always contult the manufacturer's glove seleetion guide when selecting a glove for HF, Do NOT use latex exam gloves, as they are not effective against HF. If you have any questions about selecting a glove to use for handling HF, contact an industrial bygienist from EH\&S (543-7388). Double gloving is recommended in case of leaks.

Gloves that have not been contuminated with HF may be disposed of in the common trash. If gloves become contaminated with HF, remove them immedistely, thotoughly wash your bands, and check your hands for uny sign of contamination. (Remember that contact with diluted HF solutions may nat exhibit any pain for some hours after contact). Contaminated gloves must be disposed of as HF waste.

\section{KMERGENCY RESPONSE}

Since HF is corrosive and rapidly damages tisslae, WISHA requires access to an eyewash and safety shower.

\section{SKIN CONTACT/SAFETY SHOWE.}

Spilts of HF shail be flushed for a maximum of 5 minutes. This chemical is so aggressive in its attack on skin and bone that the most important response is to apply a calcium glucoanate gel antidote as soon as possible. Remove contamimated clothing immediately (wear manuacturer recommended protective gloves when handling contarninated elothing). After 5 minutes in the safety shower, treatment of the skin with calcium glacoate gel should be initiated and continued, using manufacturer recommended gloved hands, while awaiting medical emergency treatment. Whito specks appearing around the contaminated area indicate that the desired reaction has taken place. (If cloudiness ot separation occurn, then the gel mast be re-applied.)

\section{FIRST AID TREATMENT - CALCIUM Gluconate Gri.}

Calcium gluconate gel is a topieal antidote for HF skin exposure. Calcium gluconate works by combining with HF to form insoluble calcium fluotide, thus preventing the extraction of calcium from tissues and bones and the resulting burns. Keep calcium gluconate gel uearby, whenever you're working with HF. Ulse disposable clean nitrile gloves to apply cakcium gluconate gel. EVEN AFTER AFPLYING CALCIUM GLUCONATE, 15 IS ESEENTLAL. THAT YOU SEE A FITYSICA AN RUGIT AWAY.

\section{EVE, CONTACT/EYEWASH}

The eyewash should be used for $15 \mathrm{~min}$ utes. Do not place calcium gluconate gel in the eyes. SEEK IMMEDINTE MEDICAL. ATIENTHON.

\section{TO EXPEDTIE THE EMIKRGENIEX}

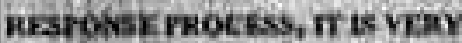
impostavr rist:

- You take this TIPS sheet and tha MSDS to the ER (Harborview, when pessiblo).

- ER personael call the Poison Cooirel for further assistance.

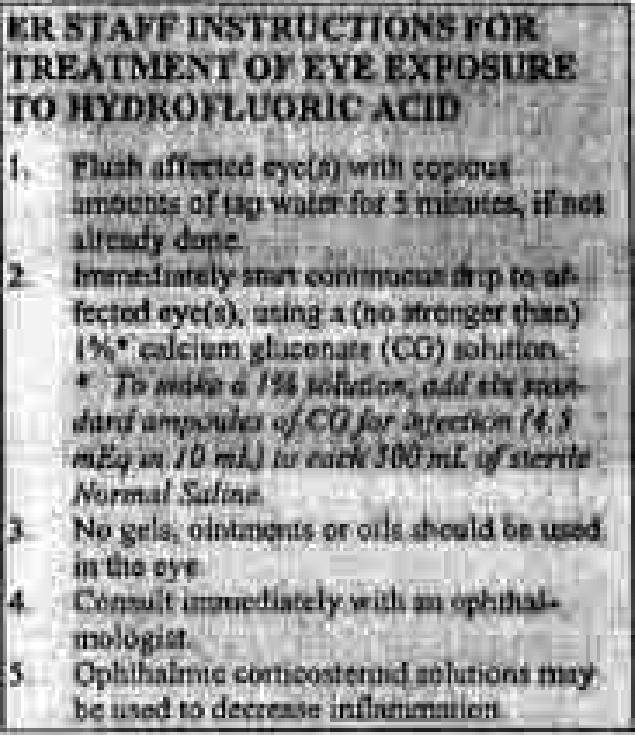

\section{HF Srits}

If HF is spilled outside of a chemical hood, evacuate the area, close the doors, post the area with a sign to prevent others from entering, and call 9-911. Attend to injured as described above. If the incident occurs during regular work hours (Mon. day-Friday, 8 a.m.-5 p.m), also call EHES at 543-0467. Sinall spills of HF inside a chemical fime hood can be newtralized with sodium bicarbonate if the workers performing the cleanup bave the correct equipment, understand the hazards, and know bow to clean up the spill safely and dispose of the waste properly.

\section{HOW TO ORDER CALCTUM GLUCONATE GEL.}

You can obtain an 8-oz, bottle $(240 \mathrm{~g}$.) of $3 \%$ calcium gluconate gel from Enviranmental Health \& Safety, by calling $543-0467$. The cost is $\$ 28.00$ (no tax). Please provide a buitget name and number. Calcum Gluconate has a 1-year shelr lifo and should be stored in a refrigerator if possible, and replaced with a fresh supply after its expiration date has pessed. The Principal lnvestigator is re. sponsible for ensuring the product is available in the lab at all times.

We suggest you purchase at least 2 botthes, as an extra bottlo should temain in the lab for staff involved in the spill cleanup.

\section{EHES CAN HEL.P}

BH\&S is available to assist with questions and training. Please cail 543-7388 for questions about the safe handling of HF 
HYDROFLUORIC ACID (HF)

- Erin McKrowh, fadustrial Hygienist

- Stuart Cordts, Industrial Hygiene Sapervisor

\section{Accidents}

- Australia

-UW

\section{Uses}

- Serface cleaning

- Mineral digestion

- Etching

- Biological staining

- Prodisction of fleorine and aluminum fluoride

\section{Hazards}

- Extremely painfal buras

- Fluoride poisoaiag

- Hypocalcemia asd hypomaguesemia

- Vestricular fibriliation

- $2 \%$ HF alse considered hazardous

- Dectiving dae to delayed onset of pais
Worker Air-borne Exposure Regulations

- Do wot exced 3 PPM at any tine

- 30 PPM is considered immediately dangereus to life and heaith

- Ahove 50 PPM exposures-even brief-may be fatal

\section{Safe Work Practices}

- Develop an SOP

- Never use HF when working alone

- De NOT eat or driak ia the lab

- Use in the fume hood

- Always wear personal protective equipmeut 


\section{Personal Protection}

- Goggles and face shield

-6. mil aitrile inaner glove

- 22 mil Ansel Edmont outer nifrile glove

- t.ali ceat and an acid resistant apron

- fong pants, ciosed-toe shoes

\section{Training}

- Train all staff in the lab. even if they do eot hasdle HF

- Document the training

- Provitie periodie refresber traisiag prier ta use

\section{What to include in training}

- Hararis

- Safe Work Practices

- PPE

- Storage

- Disposal

- Emergency Equipment

- Spall protocol

- First Aid

\section{Storage}

- Stare in potyetbylene or Teflon containers

- Iacompatible with glass, metal or ceramic containers

- Store on low protected sheif, away from caustics

\section{Disposal of HF}

- Container requirements:

- Coanpatihile with HF and in good caedition - Sealed

- Harardous waste tabel

- Chemical Collection Request Form

\section{Waste Disposal Alternative}

- Treat with calcium carbonate

- Produces a sofid non-hazardous calciam fuoride presipitate

- Trash allowed 


\section{Required Emergency Equipment}

- Safety shower (drench type) - 10 secoud access

- Eyewash

- Chemieal spit kit (N. Campas Stores)

- Calcium gituconate get (EH\&S)

\section{Safety Shower}

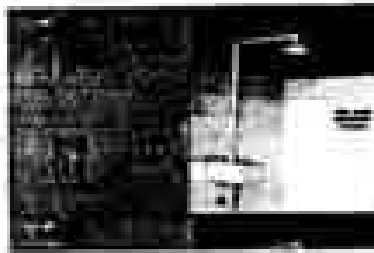

"Malataibua by Fatiliry Serven

TFeted anasiliy

- Tied a prier te use of IS

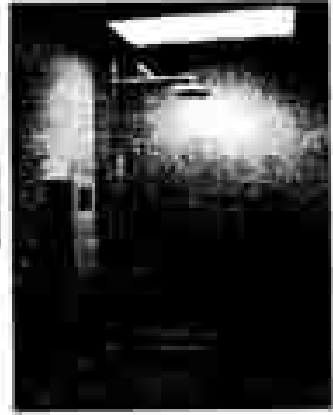

\section{Stores Chemical Spill Kit}

\section{Eye Wash}

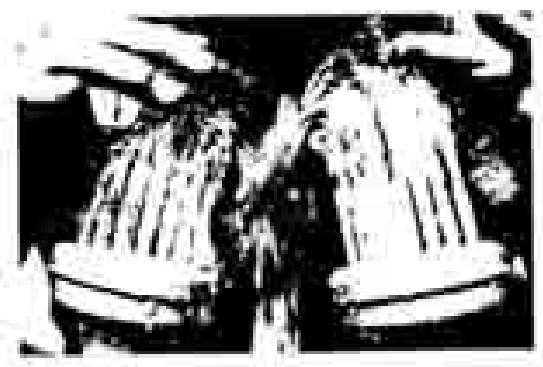

- 5 gallon container, plastic sacks

- Dust pan and whisk broom

- Nitrile gloves(6 and 22 mil), several sizes

- Gegegirs

- Sodium bicarbonate (baking soda)

- Spill pads (absorb solveats, oil, and water)

Soush Campus Stores in 7600-100 540.00

\section{Calcium Gluconate Gel Antidote}

- Purchased separately

- Topical gel combines with HF to form iasolubir calcium fuoride

- Prevents the extraction of calcium from tissues and bones

- One year expiration

- Store in a cool dry place

\section{Ordering Calcium Gluconate Gel}

- Order a 240 gram bottle of $3 \%$ calcium gluconate gel from E.HAS (3-9467)

- Cost is 528,00

- Provide a budget anae and namber.

- Piekup en 2ad floor Hall Health Center 


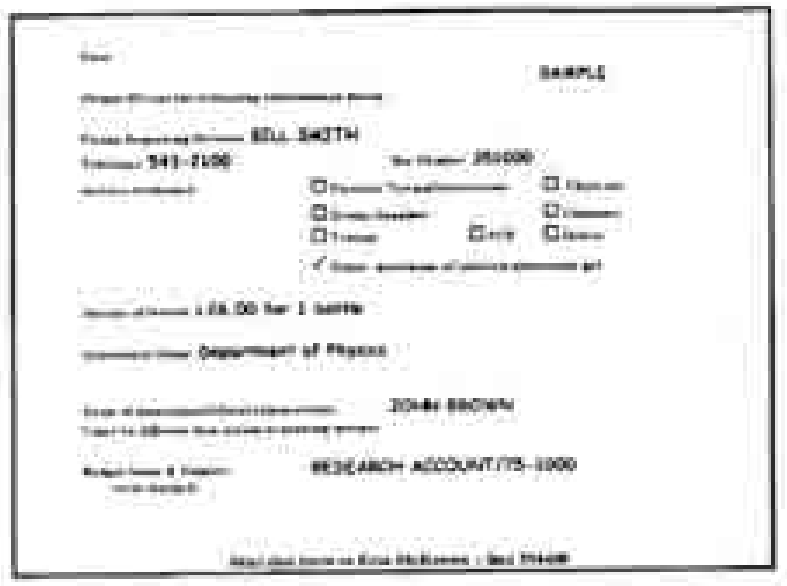

\section{Small Diluted HF Spill Cleanup}

- Double bag all cleanup materials and thoves" into thick plantic bags *

- Label as bazardous waste *

- Complete a waste collectios furm.

- Found ia the Chemieal Spill Kir

\section{Small Diluted HF Spill Cleanup}

- Neutralize with sodium bicarbanate.

- Separate glassware into glass wastr cardboard box

- Advorb remaining liquids with adsorbent nads:

nmore

- Found is the Chemical Spill Kat

\section{Large Concentrated HF Spills}

- Attend to injured

- Evacuate the area

- Pall the Fire Alarm and eall 9-911

\section{First Aid for Skin Exposure}

- Co-worker calls 9-911

- Vietim should immediately begin drenching is an emergeney safety shewer

- Remove all clothing, shoes and jevetry

\section{Skin Exposure / Safety Shower}

- Wash the sffecied area in cold water for 5 minutes wearing 22 mil nitrile gloves

- Self apply, if pessible, the calcium eluconate gel using a $22 \mathrm{mil}$ sitrile glove

- Re-apply the tel uatil medical ussistance arrives 


\section{First Aid for Inhalation of HF Gas}

- Take the victim to ciean air

- Call 9.911 and pull the fire atarm

- Inhalation may cause swelling is the respiratory tract up to 24 hrs. after exposure

\section{First Aid for Eye Exposure}

- Immediately have soutuese call 9-911

- Victim immediately proceeds to eyevash

- Flush eyes for 15 mint. holding eyelids open

- Do NOT apply calcium gluconate gel to cyes

\section{Important First Aid Tips}

- Ready access te spill kit and antidote

- All exposures require medical evaluation

- Frovide the TIPS Sheet and MSDS to medical persannel to expedite the response

- Medical persomel may call the Poisen Ceater for treatument information

\section{Summary}

- HF is uniquely laxardeus

- Specific first aid procedures and supplies

- Emergeacy respooders need information to expedite your freatment

\section{Finally, KEEP CURRENT}

- Hexafluorined is better per mfg. studies

- Not approved by the PDA yet 

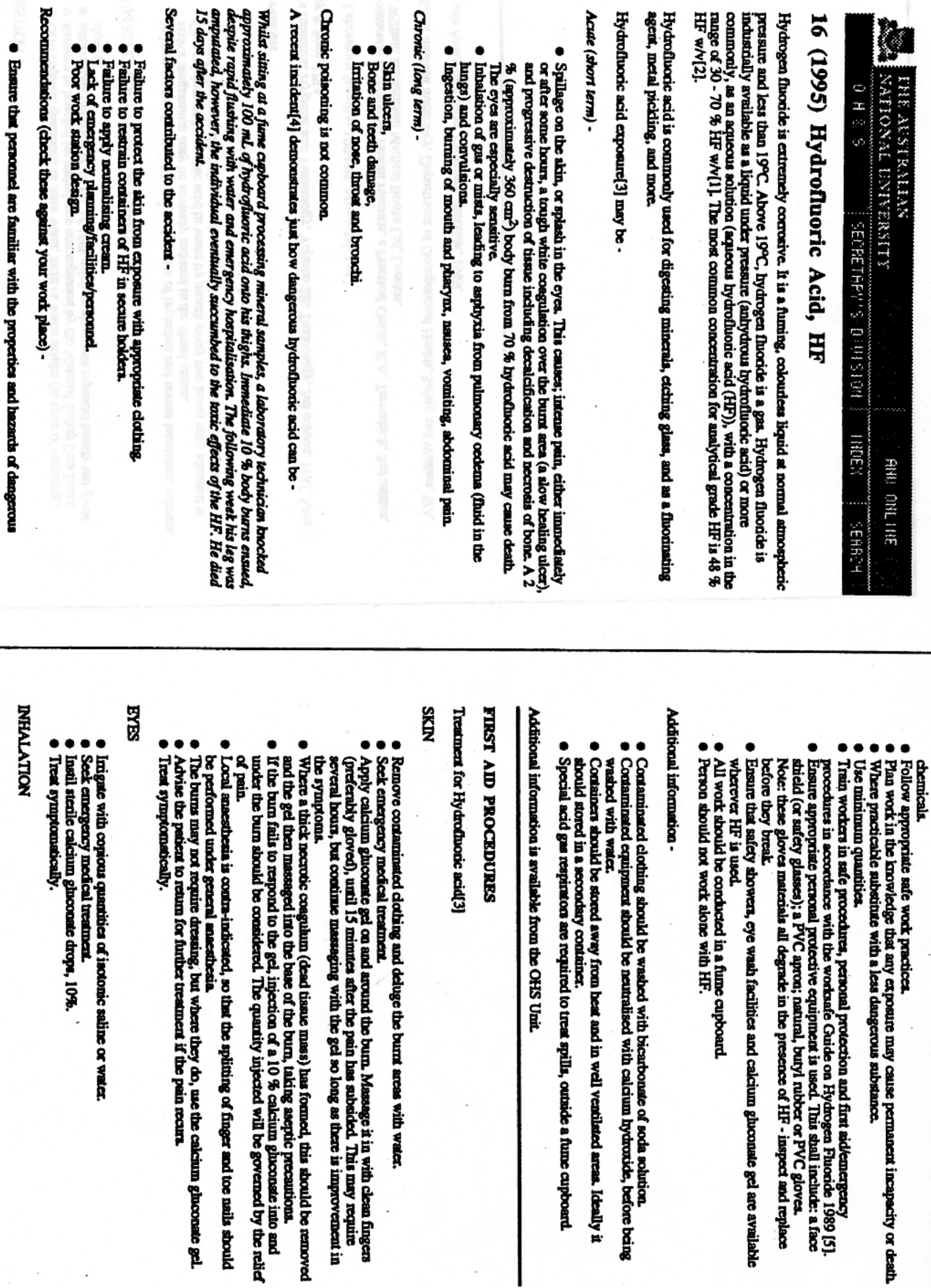


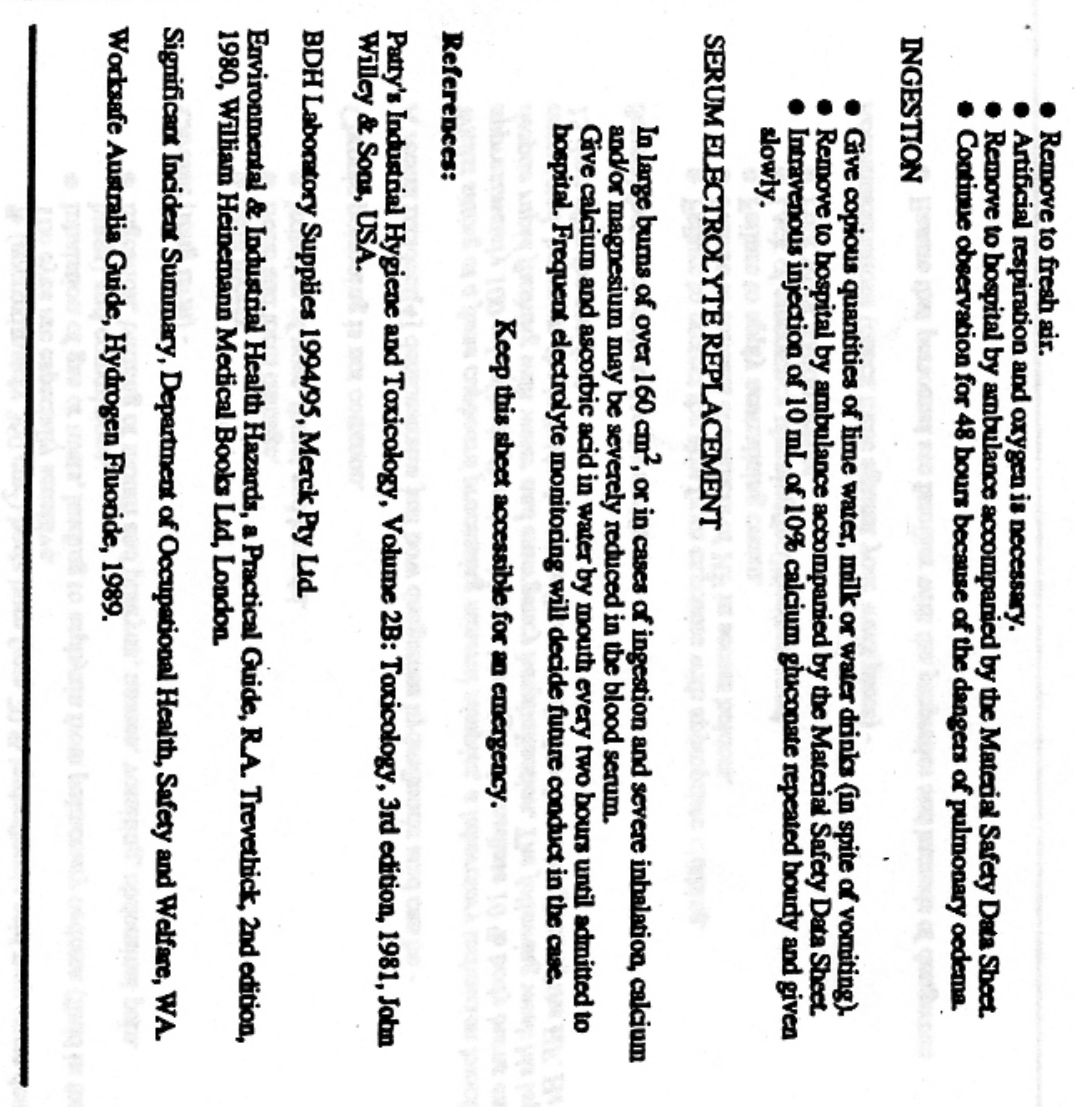


PII: S0003-4878(96)00010-5

\title{
SHORT COMMUNICATION
}

\section{FATALITY DUE TO ACUTE FLUORIDE POISONING FOLLOWING DERMAL CONTACT WITH HYDROFLUORIC ACID IN A PALYNOLOGY LABORATORY}

\author{
Luciano Muriale, * Evelyn Lee, ${ }^{*}$ John Genovese $†$ and Steven Trend* \\ *WorkSafe Western Australia, P.O. Box 294, West Perth, WA 6872, Australia; and †Chemistry Centre of \\ Western Australia, 1250 Hay Street, East Perth, WA 6004, Australia
}

(Received 6 December 1995)

\begin{abstract}
A fatal accident involving concentrated hydrofluoric acid in a palynological laboratory is described. Similar deaths due to dermal exposure to concentrated hydrofluoric acid have been reported in the literature. It is evident that rigorous control measures including proper personal protective equipment and first aid are of utmost importance in the prevention of death and injury when handling hydrofluoric acid. Possible factors that may have contributed to the accident ate reviewed. Copyright (C) 1996 British Occupational Hygiene Society.
\end{abstract}

\section{INTRODUCTION}

Hydrofluoric acid is a corrosive and toxic liquid that is potentially toxic even following dermal exposure to small amounts (Burke et al., 1973). The fatality described below highlights the potential for relatively small quantities of concentrated hydrofluoric acid to produce acute systemic toxicity and it is clear that laboratory personnel underestimated the risks associated with the acid. The purpose of this paper is to raise awareness of the inherent dangers associated with dermal contact with concentrated hydrofluoric acid, and of the importance of observing strict precautions when handling it.

\section{ACCIDENT DESCRIPTION}

A palynological technique used by geologists involves the dissolving of sedimentary rock with mineral acids (hydrochloric and hydrofluoric acid) to liberate acid-insoluble microscopic fossils. The fossils are then examined by microscopy to determine the age of the rock and oil potential.

A 37-year-old male laboratory technician was performing acid digestion of oil well core and ditch samples with $70 \% \mathrm{w} / \mathrm{w}$ concentrated hydrofluoric acid in a fume cupboard. He was believed to be seated when he knocked over a small quantity (100$230 \mathrm{ml}$ ) of hydrofluoric acid onto his lap, splashing both thighs. The only personal protective equipment (PPE) worn was two pairs of wrist length rubber gloves and a pair of polyvinyl chloride (PVC) sleeve protectors. As a result of the fact that the technician was working alone, it is unclear whether the spill was from the digestion cup or the 2-1. bulk acid container. 
The technician sustained burns to $9 \%$ of his body surface area, despite washing his legs with water from a makeshift plumbing arrangement that supplied water at $61 . \min ^{-1}$. No calcium gluconate gel was applied to the affected area and contaminated clothing was not removed during the flushing with water. Following flushing, the technician, who appeared to be in severe pain and shock, immersed himself in a chlorinated swimming pool at the rear of the workplace, where he remained for approximately $35-40$ min before ambulance help arrived.

The injured man was hypothermic and hypocalcaemic on admission to an intensive care unit at a nearby hospital, and soon became unconscious. His condition continued to deteriorate despite subcutaneous injections of calcium gluconate and adminstration of intravenous calcium and magnesium. His right leg was amputated 7 days after the incident. He subsequently died from multi-organ failure 15 days after the hydrofluoric acid spill.

\section{LIKELY CONTRIBUTING FACTORS}

The most significant factor influencing acute systemic toxicity of hydrofluoric acid is the total amount of fluoride ion absorbed. In dermal exposures this is a function of the duration of exposure, the total surface area affected and the concentration of the hydrofluoric acid (Krenzelok, 1992).

It is clear that one of the main factors that contributed to the systemic effects was the dermal exposure of $9 \%$ body surface area to concentrated hydrofluoric acid.

Wounds as small as $2.5 \%$ of the body surface area from concentrated hydrofluoric acid can produce hypocalcaemia of potentially lethal extent within 2 or $3 \mathrm{~h}$ (Greco et al., 1988). Adequate personal protective equipment during the handling of concentrated hydrofluoric acid could have prevented this death. Fulllength PVC coveralls with sleeves to the wrist or a full-length PVC apron with sleeve protectors, a face shield, rubber boots, safety goggles and mid-arm length PVC gloves should have been worn by the deceased when hydrofluoric acid was being used in the fume cupboard.

The duration of exposure may also have contributed to the uptake of the fluoride ion. Hydrofluoric acid passes through the skin into deep tissue rapidly and the affected area must be flushed with water immediately (Bracken et al., 1985; Greco et $a l,, 1988)$. The deceased did not have access to an emergency shower to remove the hydrofluoric acid, instead the skin was washed from a hose that provided water at a very low flow rate. Because of the low flow rate, the volume of water may have spread the hydrofluoric acid onto other parts of the skin, rather than washing the hydrofluoric acid off the skin. After a number of minutes, the deceased immersed himself in the swimming pool.

Although flushing is effective in removing surface hydrofluoric acid, it does not affect the fluoride ion that may have already penetrated deeper (White, 1984). In this instance, no calcium gluconate gel was applied following dermal exposure to hydrofluoric acid; calcium gluconate gel is an effective topical treatment for hydrofluoric acid burns (Trevino et al., 1983).

Even though the deceased sustained burns to $9 \%$ of body surface area inhalation may also have been another route of exposure due to the relatively high vapour 


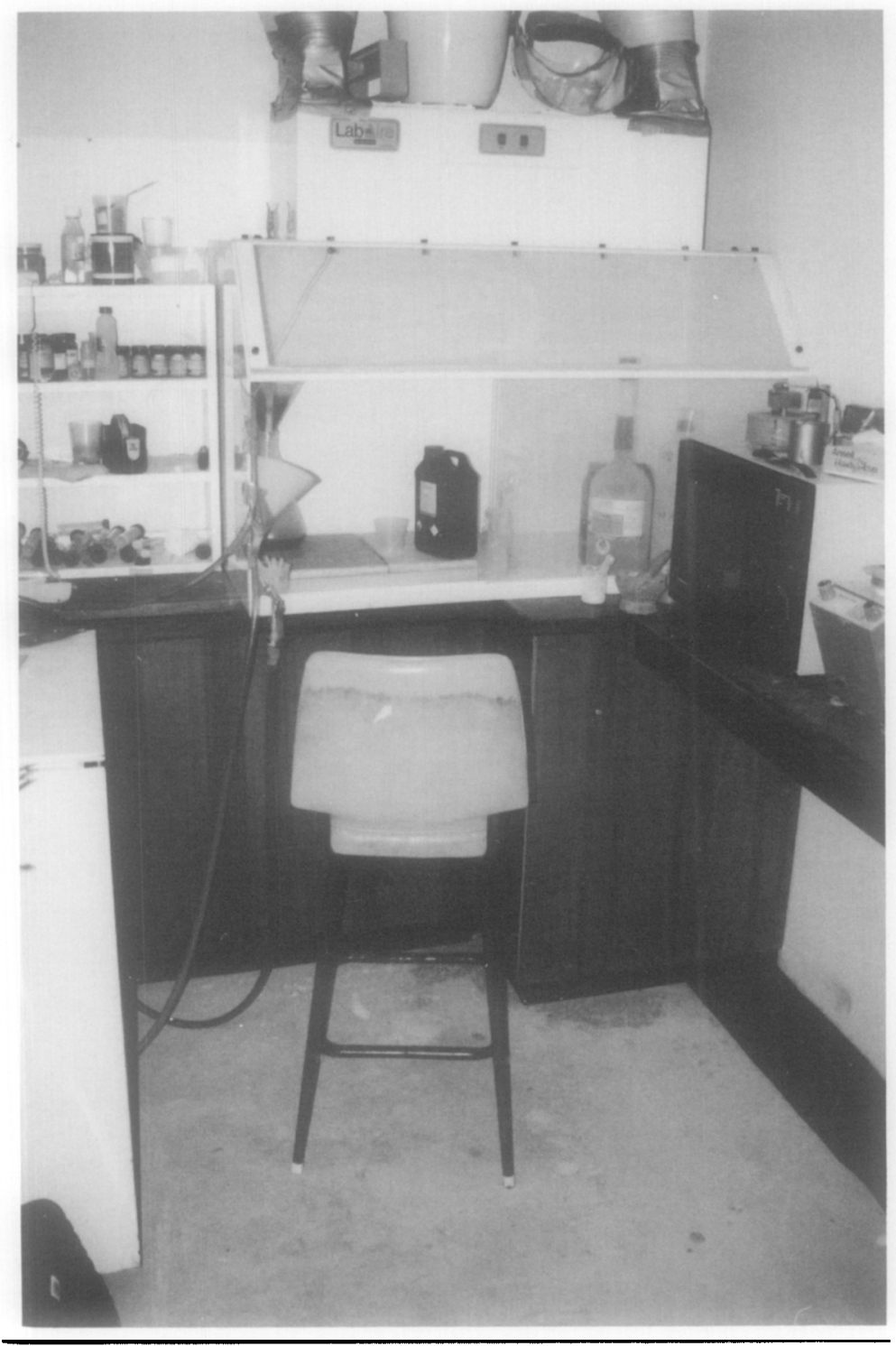

Fig. 1. Photograph of the fume cupboard where the spill of $70 \% \mathrm{w} / \mathrm{w}$ hydrofluoric acid occurred. Note the restricted space of the fume cupboard, the digestion cup and 2-1. bulk hydrofluoric acid container. 
pressure of hydrofluoric acid. Pulmonary oedema was noted at autopsy but it was unclear whether this was due to hydrofluoric acid inhalation or to other causes.

An ergonomic assessment of the work station indicated the following.

(1) The working height of the fume cupboard was too low (by between 110 and $160 \mathrm{~mm}$ ) for the deceased to work comfortably in a standing position. Sitting would have increased the body surface area during a spill of hydrofluoric acid.

(2) Instability of the digestion cups due to lightweight construction, that is, height $75 \mathrm{~mm}$, diameter of base $59 \mathrm{~mm}$, diameter at top $78 \mathrm{~mm}$ made of $2 \mathrm{~mm}$ polyethylene.

(3) Lack of available space in the fume cupboard, entrance of the fume cupboard was $470 \mathrm{~mm}$ wide and $410 \mathrm{~mm}$ high.

(4) As a result of the design of the container, decanting from the 2-1. hydrofluoric acid container was awkward, involving the pronation of the forearm.

The laboratory personnel may have minimized the likelihood of a spill through the introduction of cup supports for the digestion cups. Other ergonomic factors which may have reduced the likelihood of a spill include:

(1) provision of a fume cupboard that had more working space;

(2) use of smaller sized bottles or better designed $2-1.70 \% \mathrm{w} / \mathrm{w}$ hydrofluoric acid containers (to minimize awkward pouring postures) or introduction of a graduated dispensing unit to negate pouring the acid;

(3) provision of an appropriate bench height for the operator.

Overall, the laboratory did not comply with the requirements of Australian Standards "Safety in Laboratories" (AS 2243, 1992) Parts 1, 2 and 8 in the areas of emergency procedures, safe handling and disposal of the chemical and laboratory design.

\section{DISCUSSION AND CONCLUSION}

Mullett et al. (1987) described a similar fatality with $70 \%$ hydrofluoric acid where a 61-year-old male sustained burns to $8 \%$ of his body surface area. This individual died from cardiac arrhythmia secondary to the depletion of ionized calcium, by fluoride ion. As in the case reported here, the burns were predominantly on the right leg, the injured person washing his leg with tap water for approximately $15 \mathrm{~min}$. He reached the hospital $35 \mathrm{~min}$ after sustaining the injury. Calcium gluconate gel was not applied to the burns site until he reached the hospital and although subcutaneous and intravenous calcium therapy was given at the hospital, he died $15.5 \mathrm{~h}$ after the injury.

By contrast, Greco et al. (1988) reported the case of a 50-year-old worker who survived burns to $22 \%$ body surface area from $70 \%$ hydrofluoric acid. He showered immediately, had calcium gluconate gel applied to the wounds and was taken to a nearby hospital where he was promptly treated with subcutaneous and intravenous calcium.

It is evident that apart from the location of burns, the size of the burns and concentration of the acid, washing the area affected immediately and the application of calcium gluconate gel to reduce the uptake of fluoride ion may prevent a fatality. 
Greco et al. (1988) proposed that the development of hypocalcaemia may occur in the following situations:

(a) burns of $\geq 1 \%$ surface area from $50 \%$ (or greater concentration) hydrofluoric acid;

(b) $5 \%$ or greater surface area with any concentration of hydrofluoric acid; and

(c) inhalation of fumes from $60 \%$ (or greater concentration) hydroffuoric acid.

As noted by Stencel and Tobin (1987) and Mansdorf (1987), appropriate protective clothing, prompt first-aid and proper clean-up procedures are critical for workers handling hydrofluoric acid. Failure to wear appropriate PPE and failure to follow appropriate first-aid procedures, may result in severe injury and increase the likelihood of death from fluoride poisoning. Nearly $90 \%$ of hydrofluoric acid exposures result in the development of some toxic sequelae, and approximately $80 \%$ of patients require treatment in a health care facility (Krenzelok, 1992).

It is clear that the laboratory did not comply with relevant Australian Standards for Safety in Laboratories. Compliance with the Australian Standards would have significantly reduced the likelihood of this accident. New Australian regulations for the control of workplace substances (National Occupational Health and Safety Commission, 1994) require that a proper risk assessment is performed and it is hoped that the enforcement of these regulations will prevent fatalities such as the one described here.

Acknowledgements-The authors would like to thank WorkSafe Western Australia for permission to publish the particulars of this fatality. We are also grateful to our colleagues for their support and guidance: Dr Dino Pisaniello, Mr Martin Jennings, Dr K. C. Wan and Dr Jeff Langley.

\section{REFERENCES}

AS 2243 (1992) Safety in Laboratories, Parts 1-8. Standards Association of Australia, North Sydney.

Bracken, W. M., Cuppage, F., McLaury, R. L., Kirwan, C. and Klaassen, C. R. (1985) Comparative effectiveness of topical treatments for hydrofluoric acid burns. J. occup. Med. 7, 733-739.

Burke, W. J., Hoegg, U. R. and Phillips, R. E. (1973) Systemic fluoride poisoning resulting from a fluoride skin burn. J. occup. Med. 15, 39-41.

Greco, R. J., Hartford, C. E., Haith, L. R. and Patton, M. L. (1988) Hydrofluoric acid-induced hypocalcaemia. J. Trauma 28, 1593-1596.

Krenzelok, E. P. (1992) Hydrofluoric acid. In Hazardous Materials Toxicology: Clinical Principles of Environmental Health (Edited by Sullivan, J. B. and Krieger, G. R.). Williams and Wilkins, Baltimore.

Mansdorf, S. Z. (1987) Anhydrous hydrofluoric acid. Am. ind. Hyg. Ass. J. 48, A452.

Mullett, T., Zoeller, T., Bingham, H., Pepine, C. J., Prida, X. E., Castenholz, R. and Kirby, R. (1987) Fatal hydrofluoric acid cutaneous exposure with refractory ventricular fibrillation. JBCR 8, 216-219.

National Occupational Health and Safety Commission (1994) Control of Workplace Hazardous Substances: National Model Regulations NOHSC: 1005 (1994). Australian Government Publishing Service, Canberra.

Stencel, J. R. and Tobin, T. (1987) Hydrofluoric acid burn: Latent period was key factor. Am. ind. Hyg. Ass. J. 48, A451-A452.

Trevino, M. A., Hermann, G. H. and Sprout, W. L. (1983) Treatment of severe hydrofluoric acid exposure. J. occup. Med. 25, 861-863.

White, J. M. (1984) Hydrofluoric acid burns. Cutis 34, 241-244. 